Türk

popülasyonundaki çocuklarda kronolojik yaş, dişsel yaş ve iskelet yaşı arasındaki ilişkinin değerlendirilmesi

\section{Evaluation of relationship between chronological age, dental age and skeletal age in children of Turkish population}

\author{
Dr. Öğr. Üyesi Derya İçöz \\ Selçuk Üniversitesi, Diş Hekimliği Fakültesi, \\ Ağız, Diş ve Çene Radyolojisi A.D., Konya \\ Orcid ID: 0000-0001-8043-288X

\section{Dr. Öğr. Üyesi Hilal Özbey} \\ Pamukkale Üniversitesi, Diş Hekimliği Fakültesi, \\ Çocuk Diş Hekimliği A.D., Denizli \\ Orcid ID: 0000-0001-5661-5061
}

\section{Dr. Öğr. Üyesi Burak Kerem Apaydın}

Pamukkale Üniversitesi, Diş Hekimliği Fakültesi, Ağız, Diş ve Çene Radyolojisi A.D., Denizli

Orcid ID: 0000-0003-2621-4704

Geliş tarihi: 2 Mayıs 2019

Kabul tarihi: 9 Aralık 2019

doi: 10.5505/yeditepe.2020.59913

\section{Yazışma adresi:}

Dr. Öğr.Üyesi Derya Içcöz

Selçuk Üniversitesi, Diş Hekimliği Fakültesi,

Ağız, Diş ve Çene Radyolojisi A.D., Konya

Akademi Mahallesi, Selçuk Üniversitesi Diş Hekimliği

Fakültesi, Alaeddin Keykubat Kampüsü, İsmet Paşa

Cad. No:309, 42250 Selçuklu

Tel: +905398711624

E-posta:dyilmaz.icoz@hotmail.com

\section{ÖZET}

Amaç: Son yıllarda yaş tahmin yöntemleri, bireylerin kimliklerinin belirlenmesinin yanı sıra yasal sorumluluklar, doğum kayıtları, evlilik, iş başvuruları, cerrahi ve ortodontik tedavi planlamaları gibi birçok sebeple yaşayan bireyler için de yaygın kullanıır hale gelmiştir. Bu çalışmanın amacı Türk popülasyonundaki çocuklarda Fishman ve Willems teknikleri kullanılarak elde edilen iskelet yaşı ve dental yaşın birbirleriyle ve kronolojik yaşla ilişkisini değerlendirmekti.

Gereç ve Yöntem: Yaşları 11-15.9 arasında değişen 150 bireye ait ( $75 \mathrm{kIz}$ ve 75 erkek) el-bilek radyografları Fishman tekniğine göre ve dijital panoramik radyograflar ise Willems tekniğine göre değerlendirilerek bireylerin iskelet ve dental yaşları belirlendi. Elde edilen veriler arasındaki ilişki eşleştirilmiş örneklem $t$ testi ve Wilcoxon işaret sıralı testi kullanılarak istatistiksel olarak analiz edildi.

Bulgular: Kızlarda hem iskelet yaşı hem dental yaş kronolojik yaşa göre yüksek tahmin edilirken, erkeklerde istatistiksel olarak anlamlı fark gözlenmedi. Hem kız hem de erkeklerde iskelet yaşı dental yaşla uyumlu bulundu.

Sonuç: Erkeklerde istatistiksel olarak fark anlamlı olmamakla birlikte Türk çocuklarında, kullanılan tekniklere göre hem iskeletsel hem de dental matürasyonun erken olduğunu söylemek mümkündür.

Anahtar kelimeler: Yaş tahmini, dental yaş, iskeletsel yaş, Willems metodu, Fishman metodu.

\section{SUMMARY}

Aim: The aim of this study was to evaluate the relationship between chronological age, skeletal and dental age obtained by using Fishman and Willems techniques in Turkish population.

Materials and Methods: Hand-wrist radiographs and digital panoramic radiographs of 150 individuals ( 75 female and 75 male) aged 11-15.9 years were evaluated according to Fishman and Willems technique to determine skeletal and dental ages of individuals. The relationship between the obtained data was statistically analyzed using paired sample t test and Wilcoxon signed rank test.

Results: Both skeletal age and dental age were higher than chronological age in females and no statistically significant difference was seen in males. Skeletal and dental ages were found to be compatible for both males and females.

Conclusion: Although there is no statistically significant difference for males, it is possible to say that both the skeletal and dental maturation according to the used techniques are early in Turkish children.

Keywords: Age estimation, dental, skeletal, Willems method, Fishman method.

\section{GíRiş}

Insanın fiziksel büyümesi bir hücreyi kompleks ve olgun bir yapı haline dönüştüren olaylar dizisidir. Gelişim sürecinde herhangi bir patolojik durumun veya anomalinin tespit edilmesi ancak normal sürecin öğrenilmesiyle mümkün olmaktadır. 
Biyolojik ve fizyolojik gelişim aşamalarını değerlendirmeyi sağlayan bazı spesifik şablonlar gösteren büyüme ve gelişim, kalıtsal, fonksiyonel, çevresel özelliklere, beslenmeye ve cinsiyete bağlı, duygusal ve kültürel bir çok faktörden etkilenmektedir. ${ }^{2,3}$ Bir çocuğun kronolojik yaşı, en somut ve kolay ulaşılabilir olmasına rağmen gelişim sürecinin bireyden bireye değişiklik göstermesi sebebiyle gelişimin değerlendirilmesinde iskeletsel ve dişsel yaş kullanımı tercih edilmektedir. ${ }^{4}$ Bireylerin yaşlarının belirlenmesi; adli vakalar, doğum kayıtları, evlilik, yasal sorumluluklar, ortodontik ve cerrahi tedavi planlamaları gibi birçok sebeple önem taşımaktadır. ${ }^{4,5}$

Bireyin iskeletsel gelişimi, kemik yaşı olarak adlandırılmakta ve kemiğin boyut, şekil ve mineralizasyon derecesinin yansıması olan fizyolojik gelişimin düzeyini ifade etmektedir. ${ }^{2,6}$ Çeşitli iskelet kemikleşme merkezlerinin görünümü ve birleşimi belli bir sıra izlemekte ve bu aşamaların radyografik değerlendirmesi bireyin kemik olgunlaşması hakkında değerli bilgiler sağlamaktadır.? iskelet gelişimi genellikle el bilek radyografileri kullanılarak belirlenir, çünkü minimum maliyetle kolayca ulaşılabilir bir teknik olması ve farklı gelişim düzeyinde kemikleri bir arada değerlendirme imkanı tanıması ile gelişimin en iyi göstergesi olarak kabul edilmektedir. 8,9 Günümüze kadar el bilek radyografilerinin değerlendirilmesinde üç temel yaklaşım benimsenmiştir. Birincisi; kronolojik olarak standardize edilmiş radyografilerin oryantasyonuyla elde edilmiş atlas sistemidir. Ikincisi; birçok bireysel kemik özelliğinin aşamalarının eşleştirilmesi ve daha sonra bu aşamaların skorlanması esasına dayanmaktadır. Üçüncü teknik ise kemik şekillerinin ve el bileğin uzun kemiklerinde yapılan lineer ölçümler arasında belirlenen oranların sınıflandırılması ve daha sonra verilerin iskeletsel yaşın belirlenmesi amacıyla hesaplanmasıdır. ${ }^{8} 1982$ yılında Fishman ${ }^{10}$ iskeletsel gelişim indikatörleri belirleyerek el bilek radyografilerinden pubertal gelişim atılımını belirleyen bir teknik geliştirmiştir. Bu iskeletsel gelişim indikatörleri, bütün adölesan periyodu metodolojik bir yaklaşımla ve nispeten kolay bir şekilde değerlendirme imkanı sağlamaktadır. ${ }^{8}$

Dişsel yaşın belirlenmesi ise diş sürmesi ve diş kalsifikasyonlarının değerlendirilmesini esas alan iki farklı prensibe göre yapılabilmektedir. Bunlardan kalsifikasyon aşamalarını değerlendiren teknikler, lokal ve sistemik faktörlerden daha az etkilenme olasılığı olması sebebiyle daha güvenilir olarak kabul edilmektedir.11,12 Kalsifikasyon aşamalarının değerlendirildiği tekniklerden en sık kullanılanı 1973 yılında Demirjian ve ark ${ }^{13}$ tarafından geliştirilmiştir. Fakat farklı popülasyonlarda yapılan çalışmalarda iskeletsel yaşın ortalama yaşın üzerinde tahmin edilmesine sebep olduğundan 2001 yılında Willems ve ark ${ }^{14}$ aynı diş kalsifikasyon aşamaları için yeni bir skorlama tekniği geliştirmişlerdir.15 Türk popülasyonunda yapılan, Demirjian ve Willems tekniklerinin karşılaştırıldığı bir çalışmada Wil- lems tekniğinin Türk popülasyonu için de kronolojik yaşa daha yakın değerler verdiği sonucuna ulaşılmıştır ve bu çalışmada da bu sebeple dişsel yaşın tayini için Willems metodu tercih edilmiştir. ${ }^{16}$

Bu çalışmanın amacl; Türk popülasyonundaki çocuklarda Fishman ve Willems teknikleri kullanılarak el bilek ve panoramik radyografilerinden belirlenen iskeletsel ve dişsel yaşın kronolojik yaşla ve birbirleriyle aralarındaki ilişkiyi değerlendirmekti.

\section{GEREÇ VE YÖNTEM}

Bu çalışma, PAmukkale Üniversitesi Tıp Fakültesi Girişimsel Olmayan Klinik Araştırmalar Komitesi tarafından değerlendirilmiş ve onaylanmıştır (60116787-020/8891).

Çalışmamızda, Pamukkale Üniversitesi Diş Hekimliği Fakültesi Ağız, Diş ve Çene Radyolojisi kliniğine ortodontik şikayetlerle başvuran 150 hastaya ait ( 75 kız ve 75 erkek) dijital el bilek radyografileri ve panoramik radyografiler retrospektif olarak değerlendirilerek dahil edildi. Tüm radyografiler aynı cihaz ile (OP200D Instrumentarium Şti., Tuusula, Finlandiya), üretici firmanın talimatlarına uygun pozisyonlandırma ve ışınlama ayarlarıyla alındı ve çözünürlüğü 1920x1080 piksel olan aynı monitör üzerinde değerlendirildi (BenQ GL2460). Çalışmadan hastaların dışlanma kriterleri; radyografilerde diagnostik kalitenin düşük olması, distorsiyon tespit edilmesi, hastanın ortodontik tedavi hikayesi olması, gelişimi etkileyebilecek herhangi bir travma ya da şiddetli maloklüzyon izlenmesi, panoramik radyografilerde sol alt çenede herhangi bir sebeple 20 yaş dişi dışında diş eksikliği olması ile panoramik radyografisinin ve el bilek radyografisinin farklı günlerde çekilmiş olması olarak belirlendi. Willems ve Fishman tekniğine göre hesaplanabilen en düşük ve en yüksek yaş aralıkları göz önünde bulundurularak yanlış istatistiksel sonuçlara sebep olmaması açısından çalışma grubunun kronolojik yaşlarının 11 ila 15.9 arasındaki bireyler arasından seçilmesine dikkat edildi.10,14 Kronolojik yaş, hastanın doğum tarihi ile radyografilerinin çekildiği tarih arasındaki fark ile belirlendi.

Dişsel yaş tahmini yöntemi: Panoramik radyografiler tek bir görüntü üzerinde bir bireyin bütün dişlenme gelişimini değerlendirme imkanı sunması sebebiyle, dişsel yaş tahmini için en uygun görüntüleme tekniğidir. ${ }^{17}$ Bu çalışmada dişsel yaşın değerlendirilmesinde panoramik radyografilerde sol alt çenede bulunan yedi dişin gelişim düzeylerini esas alan Demirjian tekniğinin revize versiyonu olan Willems tekniğ $i^{14}$ kullanılmıştır. Dişsel yaş; sol mandibuler 7 dişin gelişim aşamalarının değerlendirilmesi esasına dayanan Demirjian ${ }^{13}$ tarafından geliştirilen diş kalsifikasyon aşamalarına göre kaydedildi (Tablo 1) ve Willems ve ark. ${ }^{14}$ tarafından revize edilen cinsiyete özgü tablolara göre skorlanarak hesaplandı (Tablo 2). 
Tablo 1. Demirjian tekniğine göre diş gelișim aşamalarını ve tanımlamalarını gösteren tablo.

\begin{tabular}{|c|c|}
\hline $\begin{array}{c}\text { Dental } \\
\text { gelişim } \\
\text { assamaları }\end{array}$ & Dental gelişim aşamalarımın tanımları \\
\hline A & $\begin{array}{l}\text { Kriptlerin üst seviyesinde koni formunda kalsifikasyon başlangıcı görülür. (Kalsifiye } \\
\text { noktalarda fïzyon gözlenmiyor.) }\end{array}$ \\
\hline B & $\begin{array}{l}\text { Düzenli bir okliüzal yüzey görüntüsü veren, bir veya daha fazla kaspı oluşturar } \\
\text { kalsifiye alanların füzyonu gözlenir. }\end{array}$ \\
\hline $\mathrm{C}$ & $\begin{array}{l}\text { Oklüzal yüzeyde mine ve dentin oluşumunun tamamlanması ve servikal bölgey } \\
\text { doğru birleşmesi, } \\
\text { Dentin depozisyonu görülür. } \\
\text { Pulpa odasının dıs yüzeyi oklüzal sımırda kavisli bir şekle sahiptir. }\end{array}$ \\
\hline $\mathrm{D}$ & $\begin{array}{l}\text { Mine-sement sınırına kadar kuron formasyonu tamamlanmıştır. } \\
\text { Tek köklü dişlerde pulpa odasinın superior sınırı keskin kavisli bir forma sahiptir ve } \\
\text { pulpa boynuzlanı şemsiye üstü gibidir. } \\
\text { Molarlarda pulpa odası trapezoidal formdadır. } \\
\text { Kök gelişiminin spikül şeklinde oluşum başlangıcı görülür. }\end{array}$ \\
\hline $\mathrm{E}$ & $\begin{array}{l}\text { Tek köklü dişlerde; } \\
\text { Pulpa odasının doğrusal devamll1lığı pulpa boynuzlarnyla kesintiye uğrar. } \\
\text { Kök uzunluğu kuron yükssekliğinden azdır. } \\
\text { Molarlarda; } \\
\text { Kök bifurkasyonunda noktasal ya da yanmay şeklinde kalsifikasyon görülür. } \\
\text { Kök uzunluğu kuron yüksekliğinden azdır. } \\
\end{array}$ \\
\hline $\mathrm{F}$ & $\begin{array}{l}\text { Tek köklü dişlerde; } \\
\text { Pulpa odasının formu ikizkenar üçgen gibidir ve apeks huni şeklindedir. } \\
\text { Kök uzunluğu kuron yüksekliğine eşittir ya da fazladır. } \\
\text { Molarlarda; } \\
\text { Bifurkasyon köklere huni şeklinde apeks formu verecek şekilde aşağı doğr } \\
\text { gelişmiştir. } \\
\text { Kök uzunluğu kuron yüksekliğine eşittir ya da fazladır. }\end{array}$ \\
\hline $\mathrm{G}$ & Kök kanalları birbirine paralel hale gelmiştir ve apeks parsiyel olarak açıktır. \\
\hline $\mathrm{H}$ & $\begin{array}{l}\text { Kök apeksi tamamen kapalıdır ve periodontal membran kök ve apeks çevresind } \\
\text { uniform bir genişliktedir. }\end{array}$ \\
\hline
\end{tabular}

Tablo 2. Willems metoduna göre diş gelişim aşamaları ve skorlamaları.

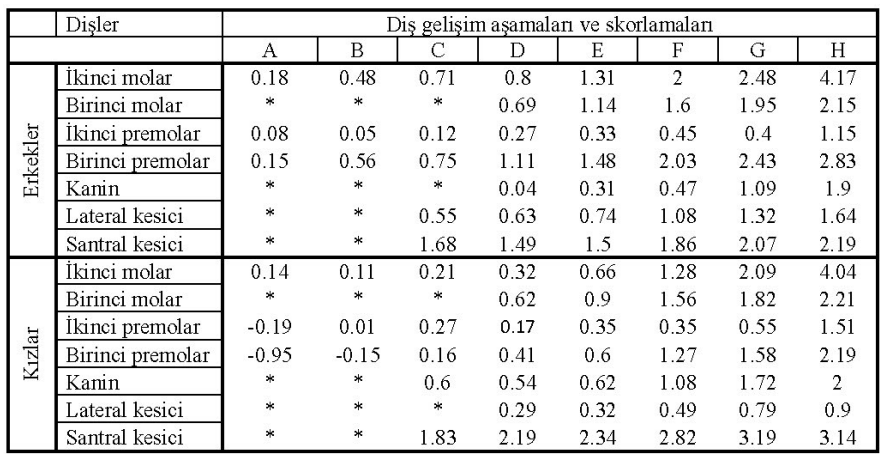

İskelet yaşı tahmini yöntemi: İskelet yaşı, Fishman tarafından geliştirilen iskeletsel gelişim düzeylerine göre on bir aşamalı bir kılavuz belirlenen Fishman tekniği ile aşamalarına göre kaydedilip, cinsiyete özgü tablolarla gelişim düzeyi yaşa dönüştürülerek belirlendi (Tablo 3). 2,17

Tablo 3. Fishman tekniğine göre gelişim aşamaları ve cinsiyete göre yaşı gösteren değerler.

\begin{tabular}{|c|c|c|c|}
\hline $\begin{array}{c}\text { İskeletsel } \\
\text { gelişim } \\
\text { aşamaları } \\
\end{array}$ & E1-bilek gelişim aşamalarmm tanmmları & Erkek & Kiz \\
\hline 1 & $\begin{array}{l}\text { Üçüncü parmağın proksimal falanksında epifiz ve diafiz } \\
\text { genişliğinin eşit olması }\end{array}$ & 11.3 & 10.2 \\
\hline 2 & $\begin{array}{l}\text { Üçüncï parmağın orta falanksında epifiz ve diafiz } \\
\text { genişliğinin eşit olması }\end{array}$ & 11.9 & 10.7 \\
\hline 3 & $\begin{array}{l}\text { Beşinci parmağın orta falanksında epifiz ve diafiz } \\
\text { genişliğinin eșit olması }\end{array}$ & 12.1 & 10.8 \\
\hline 4 & Baş parmağın addüktör sesamoidinin görünür olmas1 & 12.3 & 11.0 \\
\hline 5 & Üçüncü parmağnn distal falanksımın epifizinin kapanması & 13.0 & 11.7 \\
\hline 6 & Üçüncü parmağın orta falanksııın epifizinin kapanması & 13.7 & 11.9 \\
\hline 7 & Beşinci parmağın orta falanksımın epifizinin kapanması & 14.4 & 12.5 \\
\hline 8 & $\begin{array}{l}\text { Üçüncü parmağın distal falanksının epifiz ve diafizinin } \\
\text { füzyonu }\end{array}$ & 15.1 & 13.2 \\
\hline 9 & $\begin{array}{l}\text { ÜÇüncï parmağın proksimal falanksının epifiz ve diafïzinin } \\
\text { füzyonu }\end{array}$ & 15.4 & 13.9 \\
\hline 10 & $\begin{array}{l}\text { Üçüncü parmağın orta falanksının epifiz ve diafizinin } \\
\text { füzyonu }\end{array}$ & 16.1 & 14.8 \\
\hline 11 & Radiusun epifiz ve diafizinin fizyonu & 17.2 & 16.5 \\
\hline
\end{tabular}

Gözlemlerin tekrarlanabilirliğini analiz etmek için dişsel ve iskelet yaşları aynı gözlemci tarafından bir ay arayla iki kez ve farklı bir gözlemci tarafından da rastgele seçilen 20 panoramik ve 20 el bilek radyografisi üzerinde değerlendirildi.

\section{İstatistiksel Analiz}

Verilerin analizi SPSS 22v (Statistical Package for Social Sciences) yazııı programı ile yapıldı. Gözlemcinin birinci ve ikinci gözlemleri arasındaki uyum, sınıf-içi korelasyon katsayısı ile analiz edildi. Gözlemler arasında yüksek uyum görüldüğü için birinci gözlemler istatistiksel analiz için kullanıldı $(r=0.983)$. Elde edilen değerlerin doğruluğunu analiz etmek için rastgele seçilen 20 hastaya ait iskelet ve dişsel yaşlar ikinci bir gözlemci tarafından değerlendirildi ve gözlemcilerin değerlendirmeleri arasında yüksek uyum görüldü $(r=0.943)$.

Kronolojik yaş, dişsel yaş ve iskelet yaşı arasındaki ilişki yaş gruplarına göre Wilcoxon Signed Rank testiyle; çalışma popülasyonunun genel değerlendirilmesindeki kronolojik, dişsel ve iskelet yaşı arasındaki ilişki ise verilerin normal dağılım göstermesi sebebiyle eşleştirilmiş örneklem $\mathrm{t}$ testiyle analiz edildi. $\mathrm{p}<0.05$ istatistik olarak anlamlı kabul edildi.

\section{BULGULAR}

Bu çalışmada toplamda 11-15.9 yaş aralığındaki 150 bireye ait ( $75 \mathrm{kIz}$ ve 75 erkek) dijital el bilek ve panoramik radyografileri değerlendirildi. Veriler beş yaş grubuna (1111.9, 12-12.9, 13-13.9, 14-14.9, 15-15.9) ayrıldı ve her yaş grubundaki bireylerin eşit olması ve eşit cinsiyet dağılımı göstermesi sağlandı.

Kronolojik yaş ile iskelet yaşı ve kronolojik yaş ile dişsel yaş arasındaki ilişki kız ve erkeklerde hem genel çalışma popülasyonu için hem de her yaş grubu için ayrı ayrı olmak üzere hesaplandı. Kızlarda elde edilen bulgulara göre hem iskelet yaşı hem de dişsel yaş kronolojik yaşın üzerinde tahmin edildi. Erkeklerde ise kronolojik yaş ile dişsel ve iskelet yaşı arasında fark gözlenmedi. Yaş gruplarına göre kızlarda ve erkeklerde ortalama kronolojik yaş, iskelet yaşı ve dişsel yaş ile belirlenen yaşlar arasındaki ilişkiyi gösteren bulgular Tablo 4'te görülmektedir.

Tablo 4. Kız ve erkek çocuklarda ortalama(ort)+ standart sapma(SS) kronolojik yaş (KRN), dental yaş (DENT), iskelet yaşı (ISK) ve aralarındaki ilişkiyi gösteren tablo $(* \mathrm{p}<0.05)$.

\begin{tabular}{|c|c|c|c|c|c|c|c|c|}
\hline & $\begin{array}{c}\text { YAS } \\
\text { GRUPLARI }\end{array}$ & $\mathrm{n}$ & $\begin{array}{l}\text { KRN, ORT. } \\
\pm \text { SS }\end{array}$ & $\begin{array}{l}\text { DENT. ORT. } \\
\pm \text { SS }\end{array}$ & $\begin{array}{l}\text { isK. ORT. } \\
\text { SS }\end{array}$ & $\begin{array}{c}\text { KRN -DENT } \\
\text { P }\end{array}$ & $\underset{P}{\mathrm{KRN}-\mathrm{iSK} .}$ & $\begin{array}{c}\text { DENT-isK. } \\
\text { P }\end{array}$ \\
\hline \multirow{6}{*}{ 永 } & $11-11.9$ & 15 & $11.5 \pm 0.3$ & $12.4 \pm 0.9$ & $12.2 \pm 1.3$ & $0.012^{*}$ & $0.041^{\prime \prime}$ & 0.820 \\
\hline & $12-12.9$ & 15 & $12.5 \pm 0.3$ & $13 \pm 0.9$ & $13.1 \pm 1.4$ & 0.069 & 0.256 & 0.733 \\
\hline & $13-13.9$ & 15 & $13.5 \pm 0.3$ & $14.02 \pm 1$ & $14.2 \pm 1.4$ & $0.031^{*}$ & $0.038^{\circ}$ & 0.766 \\
\hline & $14-14.9$ & 15 & $14.4 \pm 0.3$ & $14.2 \pm 1.3$ & $14.5 \pm 0.6$ & 0.570 & 0.431 & 0.818 \\
\hline & $15-15.9$ & 15 & $15.4 \pm 0.2$ & $15.9 \pm 0.8$ & $15.4 \pm 0.9$ & $0.011^{*}$ & 0.733 & 0.65 \\
\hline & TOPLAM & 75 & $13.45+1.38$ & $13,82 \pm 1,46$ & $13,99 \pm 1,7$ & $0,004^{*}$ & $0,00^{\circ}$ & 0,315 \\
\hline \multirow{6}{*}{ 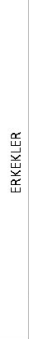 } & $11-11.9$ & 15 & $11.56 \pm 0.3$ & $12.1 \pm 1.04$ & $11.95 \pm 0.2$ & $0.041^{*}$ & $0.006^{*}$ & 0.433 \\
\hline & $12-12.9$ & 15 & $12.48 \pm 0.3$ & $12.51 \pm 1.21$ & $12.56 \pm 0.9$ & 0.977 & 0.900 & 1.000 \\
\hline & $13-13.9$ & 15 & $13.47 \pm 0.26$ & $13.81 \pm 1.13$ & $13.09 \pm 1.09$ & 0.334 & 0.211 & 0.125 \\
\hline & $14-14.9$ & 15 & $14.49 \pm 0.3$ & $14.34 \pm 1.01$ & $13.6 \pm 1.4$ & 0.733 & $0.047^{*}$ & 0.233 \\
\hline & $15-15.9$ & 15 & $15.59 \pm 0.25$ & $15.52 \pm 0.93$ & $15.59 \pm 0.77$ & 0.638 & 1.00 & 0.128 \\
\hline & TOPLAM & 75 & $13.43 \pm 1.42$ & $13,59 \pm 1,59$ & $13,27 \pm 1,51$ & 0,216 & 0,205 & 0,059 \\
\hline
\end{tabular}




\section{TARTIŞMA}

Bu çalışmanın planlanmasının amacl; bir diş hekimliği fakültesine başvuran çocuklardan seçilmiş bir çalışma grubunda kronolojik yaş, iskelet yaşı ve dişsel yaş arasındaki ilişkinin, ortodontik amaçlarla çekilmiş olan dijital panoramik ve el bilek radyografileri kullanılarak değerlendirilmesiydi. Yaş belirlenmesinde zaman içinde birçok farklı yöntem geliştirilmiş olmasına rağmen popülasyonlardaki etnik farklılıklardan dolayı evrensel bir değerlendirme sistemi belirlemek mümkün olmamıştır. Bu nedenle her tekniğin farklı popülasyonlarda test edilmesi önemlidir. ${ }^{9}$ Bu çalışmaya dahil edilen bütün radyografilerin etnik farklılık olmayan bireylerden seçilmesine dikkat edilerek, etnik açıdan tek tip bir çalışma popülasyonu elde edilmeye çalışılmış ve istatistik analizler kullanılan her iki teknik için de tekrarlanabilirliğin ve güvenilirliğin yüksek olduğunu göstermiştir. Örneklem grubu oluşturulurken yaş kriteri Fishman tekniğine göre ortalama gelişim gösteren bireylerde erkeklerde 11.3, kızlarda 10.2 alt sınırı ile erkeklerde 17.2, kızlarda 16.5 üst sınırı olması sebebiyle ve Willems tekniğine göre erkeklerde 16.03 ve kızlarda 15.99 üst sınırı olması sebebiyle her iki cinsiyet için 11 ve 15.9 yaşlar arası ile sınırlandııılmıştır.

Bireyler gelişim sürecinde önemli farklılıklar göstermektedirler ancak, biyolojik ve fizyolojik gelişimin değerlendirilmesini sağlayan bazı belirgin özellikler vardır. İskeletsel gelişim kemiğin boyut, şekil ve mineralizasyon derecesinin bir ölçüsüdür ve bireyin tam olgunluğa yakınlığıyla ilgili değerlendirme imkanı tanımaktadır. '̇skelet yaşı, kemik gelişiminin görsel muayenesine imkan tanıması, boyut ve şekil açısından kemikleşme değişiklikleriyle ilgili bilgi verme özelliği ile gelişimin değerlendirilmesinde kronolojik yaştan daha güvenilir ve kesin sonuçlar vermektedir. ${ }^{4} \mathrm{Bu}$ çalışmada iskeletsel gelişimin belirlenmesi için bireylerin el bilek radyografileri Fishman tekniğine göre değerlendirildi. Fishman tekniği el bilek radyografilerinde 6 anatomik bölgenin gelişim düzeylerini esas alarak geliştirilmiş ve daha sonra yine Fishman tarafından geliştirilen cinsiyete özgü tablolarla erken, ortalama ve geç gelişim düzeyine göre gelişim aşamaları yaşa dönüştürülmüştür., ${ }^{40,18}$ Bu çalışmada el bilek gelişim aşamaları Fishman tekniğinin ortalama gelişim düzeyi tablosu esas alınarak iskelet yaşına dönüştürülmüştür. Türk popülasyonundan seçilmiş örneklem gruplarında Fishman tekniğine göre iskelet yaşının değerlendirildiği çalışmalar olmakla birlikte literatür tarandığında Fishman tarafından geliştirilen yaş tablolarının Türk popülasyonuna uygulandığı bir çalışma tespit edilmemiştir. Bu çalışmaya dahil edilen bireyler için Fishman tekniğine göre hesaplanan iskelet yaşı ile kronolojik yaş arasında erkeklerde istatistiksel olarak önemli fark gözlenmezken kızlarda iskelet yaşı ortalama olarak 0.54 yaş daha yüksek tahmin edilmiştir. Mohammed ve ark. tarafından yapılan ve aynı yaş tablosunun kullanıldı- ğı bir çalışmada iskelet yaşının hem kadınlarda hem de erkeklerde daha düşük tahmin edildiği bulgulanmıştır. ${ }^{8}$ Çalışmamızın sonuçlarıyla oluşan farkın toplumsal farklııkların yanında söz konusu çalışmadaki yaş sınııının 9-20 arasında olmasından ve tekniğin yaş sınırları nedeniyle 16 yaş üstü hastalarda iskelet yaşının düşük tahmin edilmesinden kaynaklandığı düşünülmektedir. Bu sonuç aynı toplumda yapılan 9-13 yaş aralığındaki çalışma topluluğunun değerlendirildiği bir başka çalışmada hem kızlarda hem erkeklerde iskelet yaşının daha yüksek tahmin edilmiş olması sebebiyle de desteklenmektedir. ${ }^{19}$ Yemen toplumunda yapılmış olan bir başka araştırmada kronolojik yaş ve iskelet yaşı arasında güçlü bir ilişki olmasına rağmen, benzer şekilde her iki cinsiyette de kronolojik yaşın daha düşük tahmin edildiği tespit edilmiştir. Araştırmacılar bu durumu çevresel, genetik faktörler ve kötü beslenme şartlarıyla ilişkilendirmişlerdir. ${ }^{20}$ Bu çalışmanın sonuçlarına göre Türk toplumundan seçilmiş bu örneklem grubunda kronolojik yaş iskeletsel gelişim indeksi olarak değerlendirildiğinde kız çocuklarının erken gelişim gösterdiği söylenebilir.

Cinsiyetler arasında görülen diş olgunlaşma hızı farklılığı nedeniyle kızlarda ve erkeklerde kronolojik ve dişsel yaş arasındaki fark değiş̧iklik göstermektedir. ${ }^{21}$ Onat Altan ve ark. tarafından Willems tekniğinin Türk toplumunda uygulanabilirliğinin değerlendirildiği bir çalışmada dişsel yaşın kronolojik yaşa göre 0.34 yaş yüksek tahmin edildiği bulgusuna ulaşılmıştır. ${ }^{22}$ Bu çalışmada dişsel yaş kızlarda -0.29 ile 0.82 arasında fark gösterirken, erkeklerde 0.02 ile 0.90 yaş arasında fark göstermiştir. Bizim çalışmamızda da benzer şekilde dişsel yaş kızlarda ortalama 0.37, erkeklerde ise 0.13 yüksek tahmin edilmiş, kızlarda fark aralığı -0.2 ile 0.9 arasında, erkeklerde ise -0.15 ile 0.54 arasında bulunmuştur. 14-14.9 yaş aralığı için hem kızlarda hem erkeklerde dişsel yaş kronolojik yaşa göre daha düşük tahmin edilmiştir. Çalışmamızın bulgularına göre kızlarda dişsel gelişimin daha erken olduğu ve Willems tekniğinin erkeklerde kızlara göre daha doğru sonuç verdiği söylenebilir. Bu bulgular iki farklı etnik popülasyonun birlikte değerlendirildiği Maber ve ark. ve Priya tarafından yapılan çalışmalardaki benzer sonuçlar ile desteklenmektedir. ${ }^{23,24}$ Fakat literatürde Willems tekniğinin kızlarda daha doğru sonuçlar verdiğini gösteren çalışmalar da mevcuttur. ${ }^{1722,25-27}$ Bu farklılıklar popülasyonlara bağlı olarak etnik farklııklar, beslenme alışkanlıkları, iklim koşulları, çalışma popülasyonunu oluşturan bireylerin sosyoekonomik düzeyleri, yaş aralıkları, örneklem büyüklüğü ve kullanılan istatistik teknikleri gibi birçok faktörle ilişkilendirilebilmektedir. ${ }^{28}$

Günümüze kadar yüksek düzeyde güvenilirlik gösteren yaş tahmin yöntemleri geliştirilmiş olmasına rağmen farklı çalışma gruplarında yapılmış araştırmalar etnik farklıı̆ın yüksek ya da düşük yaş tahminine neden olarak doğru- 
luğu etkilediğini göstermiştir. ${ }^{17}$ Genetik ve çevresel etkenler, beslenme ve yaşam alışkanlıkları gibi faktörlerin toplumsal farklılıkların oluşmasına sebep olabileceği düşünülmektedir. ${ }^{20}$ Dişsel yaş ve iskelet yaşı arasındaki ilişki değerlendirildiğinde hem kIz hem erkek çocuklarda anlamlı bir fark görülmemiştir. Uysal ve ark tarafından Türk popülasyonunda yapılan ve dişsel gelişim aşamaları ile iskeletsel olgunlaşma arasındaki ilişkinin değerlendirildiği bir çalışmada dişsel ve iskeletsel gelişim arasında yüksek korelasyon gözlenmiştir. ${ }^{29}$ Türk popülasyonundaki bu sonuçlar farklı etnik kökenler üzerinde yapılan araştırmalarla da desteklenmiştir. ${ }^{30,31}$ Diğer yandan dişsel yaş ve iskelet yaşı arasında istatistiksel olarak zayıf ilişkinin belirlendiği araştırma bulguları da mevcuttur. ${ }^{32,33}$

Olgunlaşmanın değerlendirildiği çalışmalarda radyografi seçimi ve örneklem büyüklüğü, sonuçları önemli derecede etkileyebileceğinden belirlenen çalışma popülasyonu dikkatle seçilmelidir. Çalışmamıza dahil edilen bireyler dişsel gelişimi etkileyebilecek düzeyde ortodontik problemi olmayan bireylerden seçilmiş olsa da retrospektif bir çalışma olması sebebiyle büyüme gelişimle ilgili net olarak değerlendirme yapılamamış olması, bu çalışmanın önemli bir kısıtılığıdır. Bunun dışında bu çalışmanın belirli bir toplumda sınırlı popülasyon genişliği ile çalışılmış olması sebebiyle örneklem büyüklüğünün artırılıp daha farklı popülasyonlarda uygulanması literatüre katkı sağlayacağı düşünülmektedir.

\section{SONUÇ}

Erkeklerde istatistiksel olarak fark anlamlı olmamakla birlikte Türk çocuklarında, kullanılan tekniklere göre değerlendirildiğinde ortalama iskeletsel ve dişsel gelişimin erken olduğu söylenebilir. Kronolojik yaş, bireylerin gelişim durumlarıyla ilgili yaklaşık değerler vermektedir ve matürasyonun değerlendirilmesi için iskeletsel ve dişsel gelişimin dikkate alınması gerçeği daha çok yansıtmaktadır.

Bireylerin gelişimlerinin kişisel farklılıklar göstermesi nedeniyle, her birey için kesin yaşı tahmin edecek bir yaş tayin yöntemi belirlemek mümkün değildir bu nedenle farklı tekniklerle tekrarlayan hesaplamaların daha doğru sonuçlar vereceğini düşünmekteyiz.

\section{KAYNAKLAR}

1. Palanisamy V, Rao A, Shenoy R, Baranya SS. Correlation of dental age, skeletal age and chronological age among children aged 9-14 years: A retrospective study. J Indian Soc J Pedod Prev Dent 2016; 34: 310-314.

2. Mohammed RB, Kalyan VS, Tircouveluri S, Vegesna GC, Chirla A, Varma DM. The reliability of Fishman method of skeletal maturation for age estimation in children of South Indian population. J Nat Sc Biol Med 2014; 5: 297-302.

3. Kumar V, Hedge SK, Bhat SS. The relationship between dental age, bone age and chronological age in children with sort stature. Int J Contemporary Dentistry 2011; 2: 6-11.
4. Macha M, Lamba B, Avula JSS, Muthineni S, Margana PGJS, Chitoori P, et al. Estimation of correlation between chronological age, skeletal age and dental age in children - A cross-sectional study. J Clin Diagn Res 2017; 11: 1-4.

5. Suma GN, Rao BB, Annigeri RG, Dayashankara Rao JK, Goel S. Radiographic correlation of dental and skeletal age: Third molar, an age indicatior. J Forensic Dent Sci 2011; 3: 14-18.

6. Green LJ. The interrelationships among height, weight and chronological, dental and skeletal ages. Angle Orthod 1961; 31: 189-193.

7. Varghese ST, Kumar V, Paul S, Jose LK, Mathew T, Siddique $\mathrm{S}$. Estimation of dental and bone age in obese children of South India. J Int Soc Prev Community Dent 2018; 8: 153-159.

8. Mohammed RB, Reddy MAL, Jain M, Singh JR, Sanghvi $P$, Thetay AAR. Digital radiographic evaluation of hand-wrist bone maturation and prediction of age in South Indian adolescents. HAND 2014; 9: 375-383.

9. Patel PS, Chaudhary AR, Dudhia BB, Bhatia PV, Soni $N C$, Jani YV. Accuracy of two dental and one skeletal age estimation methods in 6-16 year old Gujarati children. J Forensic Dent Sci 2015; 7: 18-27.

10. Fishman LS. Radiographic evaluation of skeletal maturation. A clinically oriented method based on hand-wrist films. Angle Orthod 1982; 52: 88-112.

11. Warhekar AM, Wanjari PV, Phulambrikar T. Correlation of radiographic and chronological age in human by using Demirjian's method: A radiographic study. J Indian Acad Oral Med Radiol 2011; 23: 1-4.

12. Balwant R, Anand SC. Tooth developments: An accuracy of age estimation of radiographic methods. World $\mathrm{J}$ Med Sci 2006; 1: 130-132.

13. Demirjian A, Goldstein $H$, Tanner JM. A new system of dental age assessment. Hum Biol 1973; 45: 211-227.

14. Willems $G$, Van Olmen A, Spiessens B, Carels C. Dental age estimation in Belgian childern: Demirjian's technique revisited. J Forensic Sci 2001; 46: 893-895.

15. Kapoor AK, Thakur S, Singhal P, Chauhan D, Jayam C. Compare, evaluate and estimate chronologic age with dental age and skeletal age in 6-14-year-old Himachali children. Int J Health Allied Sci 2017; 6: 143-148.

16. Apaydın BK, Yasar F. Accuracy of the Demirjian, Willems and Cameriere Methods of estimating dental age on Turkish children. Niger J Clin Pract 2018; 21: 257-263.

17. Mohammed RB, Krishnamraju PV, Prasanth PS, Sanghvi P, Reddy MAL, Jyotsna S. Dental age estimation using Willems method: A digital orthopantomographic study. Contemp Clin Dent 2014; 5: 371-376.

18. Fishman LS. Maturational patterns and prediction during adolecence. Angle Orthod 1987; 57: 181-189.

19. Sachan K, Sharma VP, Tandon P. Correlative and comparative study of Fishman's skeletal maturity indicators 
with CVMI and chronological age in Lucknow population. Eur J Gen Dent 2012; 1: 161-165.

20. Alqadi MA, Abuaffan AH. Validity of the Demirjian and Fishman Methods for Predicting Chronological Age Amongst Yemeni Children. Sultan Qaboos University Medical Journal. 2019; 19: 26-3.

21. Moness Ali AM, Ahmed WH, Khattab NM. Applicability of Demirjian's method for dental age estimation in a group of Egyptian children. BDJ Open 2019; 5(2): doi:10.1038/ s41405-019-0015-y

22. Onat Altan $H$, Altan $A$, Bilgiç F, Akıncı Sözer $A$, Damlar i. The applicability of Willems' method for age estimation in Southern Turkish children: a preliminary study. J Forensic Leg Med 2016; 38: 24-27.

23. Maber M, Liversidge HM, Hector MP. Accuracy of age estimation of radiographic methods using developing teeth. Forensic Sci Int 2006; 159S: 68-73.

24. Priya E. Applicability of Willems method of dental age assessment in 14 years threshold children in South India - A pilot study. J Forensic Res 2015; S4: 2.

25. Ambarkova V, Galic I, Vadonavic M, Biocina-Lukenda D, Brkic H. Dental age estimation using Demirjian and Willems methods: cross-sectional study on children from the former Yugoslav Republic of Macedonia. Forensic Sci Int 2014; 234: 187.e1-7.

26. Galic I, Vadonovic M, Cameriere R, Nakas E, Galic E, Selimovic E, ve ark. Accuracy of Cameriere Haavikko and Willems radiographic methods on age estimation on Bosnian- Herzegovian children age groups 6-13. Int J Legal Med 2011; 125: 315-321.

27. El-Bakary AA, Hammad SM, Mohammed F. Dental age estimation in Egyptian children, comparison between two methods. J Forensic Leg Med 2010; 17: 363-367.

28. Gungor OE, Kale B, Celikoglu M, Gungor AY, Sarı Z. Validity of Demirjian method for dental age estimation for Southern Turkish children. Niger J Clin Pract 2015; 18 : 616-619.

29. Uysal T, Sarı Z, Ramoğlu SI, Başçiftçi FA. Relationships between dental and skeletal maturity in Turkish subjects. Angle Orthod 2004; 74: 657-664.

30. Krailassiri S, Anuwongnukroh N, Dechkunakorn S. Relationship between dental calcification stages and skeletal maturity indicators in Thai individuals. Angle Orthod 2002; 72: 155-166.

31. Engström $C$, Engström $H$, Sagne $S$. Lower third molar development in relation to skeletal maturity and chronological age. Angle Orthod 1983; 53: 97-106.

32. Lewis $A B$, Garn SM. The relationship between tooth formation and other maturational factors. Angle Orthod 1960; 30: 70-77.

33. Garn SM, Lewis AB, Bonne B. Third molar formation and its developmental course. Angle Orthod 1962; 44:

270-27. 